\title{
OPTIMASI PERENCANAAN PRODUKSI CRUMB RUBBER DENGAN METODE GOAL PROGRAMMING DI PT. BAKRIE SUMATERA PLANTATIONS TBK
}

\author{
Syamsul Bahri*, Sri Meutia dan Devita Sari \\ Jurusan Teknik Industri, Fakultas Teknik, Universitas Malikussaleh, Lhokseumawe, Indonesia \\ ${ }^{*}$ Corresponding Author: Irsyamsul.bahri@unimal.ac.id
}

\begin{abstract}
Abstrak - Di era pasar bebas yang penuh dengan persaingan yang ketat, menjadi suatu kewajiban bagi setiap perusahaan untuk mampu bertahan dengan persaingan yang ada dengan jalan selalu meningkatkan efektifitas dan efisiensinya dalam menjalankan produksi. Untuk memenuhi permintaaan pasar, maka perlu dilakukan perencanaan produksi secara optimal dengan menggunakan metode Goal Programming. Metode peramalan yang digunakan berdasarkan nilai Standart Error terkecil adalah metode Exponential Smoothing yaitu untuk SIR 3L sebesar 106172.3, SIR 10 sebesar 83057.05 dan SIR 20 sebesar 68598.16. Hasil dari metode Goal Programming menunjukkan bahwa sebagian dari hasil perencanaan produksi crumb rubber untuk SIR 3L, SIR 10 dan SIR 20 tahun 2020 di PT. Bakrie Sumatera Plantations Tbk. sudah memenuhi target perusahaan.
\end{abstract}

Kata Kunci: Crumb Rubber; produksi; perencanaan; goal programming.

\section{Pendahuluan}

Di era pasar bebas yang penuh dengan persaingan yang ketat, menjadi suatu kewajiban bagi setiap perusahaan untuk mampu bertahan dengan persaingan yang ada dengan jalan selalu meningkatkan efektifitas dan efisiensinya dalam menjalankan produksi.

PT. Bakrie Sumatera Plantations merupakan perusahaan bergerak dalam pengolahan karet mentah menjadi bahan setengah jadi (crumb rubber) yang di ekspor ke luar negeri.

Produksi Crumb Rubber SIR 3L, SIR 10, dan SIR 20 mengalami fluktuasi di setiap bulannya dengan angka penurunan tertinggi untuk Crumb Rubber SIR 3L yaitu sebesar $85.22 \%$ pada bulan Oktober tahun 2017, Crumb Rubber SIR 10 yaitu sebesar $81.22 \%$ pada bulan November tahun 2017 dan Crumb Rubber SIR 20 sebesar $100 \%$ atau sama dengan non produksi pada bulan Januari tahun 2019. Untuk itu diperlukan perencanaan produksi agar perusahaan dapat memenuhi permintaan pasar. Berdasarkan permasalahan yang ada, maka saya mengambil judul"Optimasi perencanaan produksi Crumb Rubber dengan metode Goal Programming di PT. Bakrie Sumatera Plantations Tbk." .

Adapun tujuan yang ingin dicapai dalam melakukan penelitian ini adalah sebagai berikut:
1. Untuk menentukan hasil peramalan produksi SIR 10 dan SIR 20 Tahun 2020 di PT. Bakrie Sumatera Plantations Tbk.

2. Untuk menentukan hasil perencanaan produksi untuk SIR 10 dan SIR 20 Tahun 2020 di PT. Bakrie Sumatera Plantations Tbk.

3. Untuk mengetahui kesesuaian hasil perencanaan produksi dengan target perusahaan.

\section{Tinjauan Pustaka}

Perencanaan produksi adalah ativitas untuk menetapkan produk yang di produksi, jumlah yang dibutuhkan, kapan produk tersebut harus selesai dan sumber-sumber yang dibutuhkan. Kegiatan ini salah satu kegiatan dari manajemen perusahaan, dimana manajemen memberikan solusi kepada pimpinan [1]. Solusi dari manajemen dapat berupa penentuan tindakan atau usaha yang perlu diambil pimpinan dengan mempertimbangkan masalah yang akan timbul pada saat proses produksi ataupun dimasa yang akan datang. Perencanaan proses produksi meliputi perencanaan dan pengorganisasian orangorang, bahan-bahan, mesin-mesin, peralatan serta modal yang diperlukan untuk melakukan proses produksi [2]. 


\section{Linear Programming}

Linear Programming adalah suatu tehnik penyelesaian optimal atas suatu problema keputusan dengan cara menentukan terlebih dahulu fungsi tujuan (memaksimalkan atau meminimalkan) dan kendalakendala yang ada ke dalam model matematik persamaan linear. Linear Programming sering digunakan dalam menyelesaikan problema-problema alokasi sumber daya, seperti dalam bidang manufakturing, pemasaran, keuangan, personalia, administrasi dan lain sebagainya. [3] Model Goal programming merupakan perluasan dari model pemrograman linear, sehingga seluruh asumsi, notasi, formulasi model matematis, prosedur perumusaan model dan penyelesaiannya tidak berbeda. Perbedaan hanya terletak pada kehadiran sepasang variabel deviasional yang akan muncul di fungsi tujuan dan di fungsi-fungsi kendala. [4]

Oleh karena itu, konsep dasar pemrograman linear akan selalu melandasi pembahasan model goal programming. Langkah-langkah pembuatan model program linear (Linear Programming) adalah sebagai berikut :

1. Tentukan variabel-variabel keputusan. Variabel keputusan adalah besaran yang harus ditentukan nilainya agar optimalitas yang diinginkan tercapai

2. Buatlah fungsi sasaran yaitu fungsi yang akan dioptimumkan. Fungsi ini harus merupakan kombinasi linear variabel-variabel keputusan.

3. Tentukan kendala berdasarkan keterbatasan sumber daya atau karena kondisi yang harus terpenuhi. Seperti halnya fungsi sasaran, fungsi setiap kendala harus merupakan fungsi linear variabel keputusan. kendala bisa berupa suatu persamaan atau pertidaksamaan.[5] Model umum Linear Programming dapat dirumuskan ke dalam bentuk matematik sebagai berikut :

Minimumkan $z=c_{1} x_{1}+c_{2} x_{2}+\ldots+c_{n} x_{n}$ berdasarkan pembatas :

$$
\begin{aligned}
& a_{11} x_{1}+a_{12} x_{2}+\ldots+a_{1 n} x_{n} \leq b_{1} \\
& 21 x_{1}+a_{22} x_{2}+\ldots+a_{2 n} x_{n} \leq b_{2} \\
& a_{m 1} x_{1}+a_{m 2} x_{2}+\ldots+a_{m n} x_{n} \leq b_{m} \\
& x_{i} \geq 0(i=1,2, \ldots, n)
\end{aligned}
$$

Keterangan:

$$
\begin{aligned}
& z=\text { Fungsi tujuan. } \\
& c_{n}=\text { Koefisien variabelkeputusan. } \\
& x_{n}=\text { Variabel keputusan } \\
& m=\text { Macam batasan-batasan sumber atau fasilitas yang } \\
& \text { tersedia } \\
& n=\text { Macam-macam kegiatanyang menggunakansumberatau } \\
& \text { fasilitastersebut. } \\
& I=\text { Nomor setiap macam sumber atau fasilitas yangtersedia } \\
& (1,2,3, \ldots, m)
\end{aligned}
$$

j =Nomor setiap macam kegiatan yang menggunakan sumber atau fasilitas yang tersedia (1,2,3,...,n). [6]

Maka hal ini dapat diselesaikan dengan model Goal Programming sebagai berikut:

Minimumkan:

$$
\begin{array}{r}
Z=P_{1}\left(d^{+}+d^{-}\right)+P\left(d^{+}+d^{-}\right)+\ldots .+ \\
P\left(d^{+}+d^{-}\right) \ldots \ldots \ldots \ldots \ldots \ldots \ldots \ldots \ldots \ldots \ldots \ldots \ldots \ldots \ldots \ldots \ldots \ldots
\end{array}
$$

Berdasarkan pembatas:

$$
\sum_{i=1}^{n} a_{i} X_{i}+d_{1}^{+}+d_{1}^{-} \leq Y_{i}
$$

$$
\begin{aligned}
& P_{i}=\text { Tujuan-tujuan yang ingin dicapai } \\
& d^{+}=\text {Penyimpangan negatif } \\
& d^{-} \overline{\overline{1}} \text { Penyimpangan positif }
\end{aligned}
$$

\section{Goal Programming}

Model goal programming sudah sering dipergunakan dalam penelitian-penelitian terdahulu untuk pemodelan masalah multi sasaran.[7] Goal programming merupakan salah satu model matematis yang dapat dipergunakan sebagai dasar dalam pengambilan keputusan untuk menganalisis dan membuat solusi persoalan yang melibatkan banyak sasaran sehingga diperoleh solusi yang optimal. [8] Aran Puntosadewo (2013) mengatakan bahwa pendekatan dasar goal programming adalah untuk menetapkan suatu tujuan yang dinyatakan dengan angka tertentu untuk setiap tujuan, merumuskan suatu fungsi tujuan untuk setiap tujuan, dan kemudian mencari penyelesaian yang meminimumkan jumlah (tertimbang) penyimpangan-penyimapangan pada fungsi tujuan. Model goal programming berusaha untuk meminimumkan deviasi diantara berbagai tujuan atau sasaran yang telah ditentukan sebagai targetnya, maksudnya nilai ruas kiri persamaan kendala sebisa mungkin mendekati nilai ruas kanannya. Model goal programming merupakan perluasan dari model pemograman linier yang dikembangkan oleh A. Charles dan W. M. Cooper pada tahun 1956 sehingga seluruh asumsi, notasi, formulasi matematika, prosedur perumusan model dan penyelesaian tidak berbeda. Perbedaannya hanya terletak pada kehadiran sepasang variabel deviasional yang akan muncul difungsi tujuan dan fungsi kendala. [9] Pemrograman linier sendiri adalah sebuah model matematis yang dipergunakan untuk menemukan suatu penyelesaian optimal dengan cara memaksimumkan atau meminimumkan fungsi tujuan terhadap satu kendala susunan. Model goal programming mempunyai tiga unsur utama, yaitu variable keputusan, fungsi tujuan dan fungsi kendala. [10]

\section{Metodelogi Penelitian}

Penelitian dilakukan di PT. Bakrie Sumatera Plantations yang merupakan salah satu anggota Kelompok Usaha Bakrie yang termasuk perusahaan 
swasta nasional pertama di Indonesia. Nama PT Bakrie Sumatera Utara Plantations Tbk yang berkedudukan di Jalan Ir. Juanda Kisaran, kabupaten Asahan Sumatera Utara dan kegiatan produksi (pengolahan karet) yang disebut Pabrik Bunut berlokasi di Kelurahan Bunut, Kecamatan Kisaran Barat, Kabupaten Asahan.

\section{Hasil Dan Pembahasan}

Data yang diambil dalam penelitian ini adalah data produksi Crumb Rubber SIR 10 dan SIR 20 tahun 2019. Adapun data produksi Crumb Rubber SIR 3L, SIR 10 dan SIR 20 tahun 2019 dapat dilihat pada tabel 1 berikut:

Tabel 1. Produksi Crumb Rubber SIR 3L, SIR 10 dan SIR 20 tahun 2019

\begin{tabular}{llll}
\hline Periode & SIR 3L & SIR 10 & SIR 20 \\
\hline Januari & 153.825 & 254.520 & 0 \\
Februari & 231.140 & 216.335 & 20.160 \\
Maret & 0 & 58.135 & 140.525 \\
April & 0 & 26.285 & 105.105 \\
Mei & 15.540 & 185.290 & 13.335 \\
Juni & 55.685 & 180.110 & 42.350 \\
Juli & 191.490 & 186.480 & 64.155 \\
Agustus & 222.630 & 166.320 & 172.305 \\
September & 127.715 & 201.355 & 66.430 \\
Oktober & 62.195 & 163.345 & 80.640 \\
November & 0 & 254.660 & 78.120 \\
Desember & 102.970 & 281.295 & 37.100 \\
\hline Total & 1.163 .190 & 2.174 .130 & 820.225 \\
\hline Sumber: Schedule produksi Crumb Rubber
\end{tabular}

\section{Data Waktu Kerja}

Waktu kerja karyawan dibagi menjadi 2 shiff yaitu setiap harinya. Sedangkan waktu kerja pada Crumb Rubber Factory sebanyak 6 hari dalam seminggu, yaitu Senin sampai dengan Sabtu yang dapat dilihat pada tabel 2 berikut:

Tabel 2. Tabel Jam Kerja

\begin{tabular}{lll}
\hline No & Shiff Kerja & Jam Kerja \\
\hline & & $07.00-09.00$ \\
$1 . \quad$ Shiff I & $09.00-12.00$ \\
& & $14.00-16.00$ \\
& & $16.00-18.00$
\end{tabular}

2. Shift II

$20.00-22.00$

Sumber: Schedule Jam Kerja Karyawan

Dalam produksi optimal terdapat tujuan-tujuan yang ingin dicapai oleh perusahan. Pada fungsi tujuan terdapat koefisien tujuan yang sesuai dengan tujuan yang ingin dicapai. Perumusan fungsi tujuan dari metode goal programming sebagai berikut:

1. Kendala sasaran memaksimumkan jumlah produksi

$\operatorname{Min} \mathrm{Z}=\sum d_{i}^{-}-d_{i}^{+}$

Min Z $=d_{1}{ }^{-}-d_{1}{ }^{+}$.......... (Pers.4.1)

$\operatorname{Min} \mathrm{Z}=d_{2}{ }^{-}-d_{2}{ }^{+}$..........(Pers.4.2)

Min Z $=d_{3}{ }^{-}-d_{3}{ }^{+}$.............(Pers.4.3)

2. Mengoptimalkan pendapatan

Mengoptimalkan pendapatan adalah keinginan setiap perusahaan. Dengan asumsi bahwa harga SIR 10 sama dengan harga 2 kali SIR 3L dan SIR 20 sama dengan 2 kali SIR 10. Jika diasumskan harga Crumb Rubber SIR $3 \mathrm{~L}$ adalah sebesar Rp. 5.000, maka fungsi sasaran dapat dituliskan sebagai berikut:

Max Z $=5.000 X_{1}+10.000 X_{2}+20.000 X_{3}$ $5.000 X_{1}+10.000 X_{2}+20.000 X_{3}+d_{4}{ }^{-}=$ 1.000 .000 .000

Min $Z=d_{4}{ }^{-}$................(Pers.4.4)

3. Memaksimalkan penggunaan mesin

Perusahaan ingin memaksimalkan penggunaan mesin, maka fungsi tujuannya adalah meminimalkan angka penyimpangan negatif $\left(d_{i}{ }^{-}\right)$untuk memaksimalkan kapasitas penggunaan mesin per bulan yaitu sebesar 79.200 menit seperti yang telah ditunjukkan pada persamaan (4.5) menjadi sebagai berikut:

$$
\begin{aligned}
& 0.1 X_{1}+0.1 X_{2}+0.1 X_{3}+d_{5}{ }^{-}-d_{5}{ }^{+}=79200 \\
& \text { Min } Z=d_{5}{ }^{-} \text {............... (Pers.4.5) }
\end{aligned}
$$

4. Meminimalkan Jam Kerja Lembur

Proses produksi yang ideal menurut perusahaan adalah produksi yang berlangsung pada jam efektif kerja, sehingga perusahaan berusaha meminimalkan jam lembur untuk mengurangi beban yang ditimbulkan dalam peranannya menambah biaya produksi. Kerena $\left(\mathrm{di}^{+}\right)$adalah nilai penyimpangan diatas kapasitas jam kerja reguler, maka nilai $\left(d_{i}{ }^{+}\right)$harus dikendalikan agar tidak melebihi kapasitas maksimal yang dapat diuraikan menjadi sebagai berikut:

$d_{6}{ }^{+} \leq 1200$

Maka fungsi tujuannya adalah untuk meminimumkan nilai $\left(d_{i}{ }^{+}\right)$seperti yang telah ditunjukkan pada persamaan 4.6, yaitu:

$\operatorname{Min} Z=d_{6}{ }^{+}$ ..(Pers.4.6)

\section{Hasil Rekapitulasi Perhitungan Metode Goal Programming}

Adapun hasil dari rekapitulasi penggunaan software QM For Windows V5 dalam hal perencanaan prduksi Crumb Rubber SIR 3L, SIR 10 dan SIR 20 dapat kita lihat sebagai berikut: 
1. Hasil produksi optimal

Adapun hasil produksi optimal dengan pembulatan dapat kita lihat pada tabel 3 berikut:

Tabel 3. Hasil Produksi Optimal Tahun 2020

\begin{tabular}{lccc}
\hline Periode & $\begin{array}{c}\text { Produksi } \\
\text { Optimal SIR } \\
\text { 3L }\end{array}$ & $\begin{array}{c}\text { Produksi } \\
\text { Optimal } \\
\text { SIR 10 }\end{array}$ & $\begin{array}{c}\text { Produksi } \\
\text { Optimal } \\
\text { SIR 20 }\end{array}$ \\
\hline Januari & 89.215 & 204.225 & 20.160 \\
Februari & 121.520 & 206.740 & 19.152 \\
Maret & 176.330 & 207.220 & 19.202 \\
April & 88.165 & 199.765 & 25.269 \\
Mei & $44.082,5$ & 191.091 & 29.260 \\
Juni & $29.811,25$ & 190.801 & 28.464 \\
Juli & $42.748,13$ & 190.267 & 29.158 \\
Agustus & $117.119,1$ & 190.077 & 30.908 \\
September & $169.874,5$ & 188.890 & 37.978 \\
Oktober & $148.794,8$ & 189.513 & 39.401 \\
November & $105.494,9$ & 188.204 & 41.463 \\
Desember & $54.747,44$. & 191.527 & 43.295 \\
\hline Total & 1.133 .155 & 2.338 .320 & 363.710 \\
\hline Rata-Rata & $94.429,59$ & 194.860 & $30.309,17$ \\
\hline
\end{tabular}

2. Hasil Pendapatan Optimal

Hasil pendapatan optimal berdasarkan asumsi bahwa harga jual produk $X_{2}=2 X_{1}$ dan $X_{3}=2 X_{2}$. Pada penelitian ini, penulis menggunakan asumsi bahwa harga jual sebuah produk Crumb Rubber SIR $3 \mathrm{~L}$ adalah Rp. 5.000. Adapun hasil keuntungan optimal berdasarkan harga tersebut dapat kita ihat pada tabel 4 berikut ini:

Tabel 4. Hasil Pendapatan Optimal

\begin{tabular}{lc}
\hline Periode & $\begin{array}{c}\text { Keuntungan } \\
\text { (Rupiah) }\end{array}$ \\
\hline Januari & 2.891 .525 .000 \\
Februari & 3.058 .040 .000 \\
Maret & 3.337 .890 .000 \\
April & 2.943 .855 .000 \\
Mei & 2.716 .525 .000 \\
Juni & 2.626 .345 .000 \\
Juli & 2.699 .560 .000 \\
Agustus & 3.104 .525 .000 \\
September & 3.497 .835 .000 \\
Oktober & 3.427 .125 .000 \\
November & 3.238 .775 .000 \\
Desember & 3.054 .905 .000 \\
\hline Total & 36.596 .905 .000 \\
Rata-Rata & 3.049 .742 .083 \\
\hline
\end{tabular}

Berdasarkan tabel 4, sasaran untuk memaksimalkan pendapatan perusahaan untuk produksi SIR 3L, SIR 10, dan SIR 20 sudah tercapai dan memenuhi target perusahaan yaitu $\geq$ Rp 1.000.000.000 per bulannya.

\section{Hasil Jam Kerja Mesin Optimal}

Adapun hasil jam kerja mesin optimal dengan pembulatan dapat kita lihat pada tabel 5 berikut:

Tabel 5. Hasil Jam Kerja Mesin Optimal

\begin{tabular}{lc}
\hline \multicolumn{1}{c}{ Periode } & $\begin{array}{c}\text { Jam Kerja Mesin } \\
\text { (Jam) }\end{array}$ \\
\hline Januari & 47.840 \\
Februari & 44.459 \\
Maret & 38.925 \\
April & 47.880 \\
Mei & 52.757 \\
Juni & 54.292 \\
Juli & 52.983 \\
Agustus & 45.390 \\
September & 39.526 \\
Oktober & 41.429 \\
November & 45.684 \\
Desember & 50.243 \\
\hline Total & 561.408 \\
Rata-Rata & 46.784 \\
\hline
\end{tabular}

Berdasarkan tabel 5, sasaran untuk mengoptimalkan jam kerja mesin untuk produksi SIR 3L, SIR 10, dan SIR 20 belum tercapai karena masih ada rata-rata sisa jam kerja sebesar 46.784 jam per bulannya yang harus dioptimalkan.

\section{Hasil Jam Kerja Lembur Optimal}

Adapun hasil jam kerja karyawan optimal dengan pembulatan dapat kita lihat pada tabel 6 berikut:

\begin{tabular}{lc}
$\begin{array}{l}\text { Tabel 6. Hasil Jam Kerja Karyawan Optimal } \\
\text { Periode }\end{array}$ & $\begin{array}{c}\text { Jam Kerja Karyawan } \\
\text { (Jam) }\end{array}$ \\
\hline Januari & 1.200 \\
Februari & 1.200 \\
Maret & 1.200 \\
April & 1.200 \\
Mei & 1.200 \\
Juni & 1.200 \\
Juli & 1.200 \\
Agustus & 1.200 \\
September & 1.200 \\
Oktober & 1.200 \\
November & 1.200 \\
Desember & 1.200 \\
\hline Total & 2.400 \\
Rata-Rata & 1.200 \\
\hline
\end{tabular}

Berdasarkan tabel 6, sasaran untuk meminimalkan jam kerja lembur untuk produksi SIR 3L, SIR 10, dan SIR 20 sudah tercapai dan memenuhi target minimal perusahaan yaitu sebesar 1.200 jam/bulannya 


\section{Kesimpulan}

Kesimpulan dari optimasi perencanaan produksi crumb rubber dengan metode Goal Programming di PT. Bakrie Sumatera Plantation Tbk. adalah sebagai berikut: Metode peramalan yang digunakan berdasarkan nilai Standart Error terkecil adalah metode Exponential Smoothing yaitu untuk SIR 3L, SIR 10 dan SIR 20 secara berturut-turut adalah 106172.3, 83057.05, 68598.16.

Hasil dari optimasi perencanaan produksi crumb rubber SIR 3L, SIR 10 dan SIR 20 dari bulan Januari sampai dengan bulan Desember 2020 di PT. Bakrie Sumatera Plantations Tbk. adalah sebagai berikut:

a. Sasaran untuk mengoptimalkan jumlah produksi crumb rubber SIR 3L, SIR 10 dan SIR 20 dari bulan Januari sampai dengan bulan Desember tahun 2020 sudah tercapai karena total penyimpangan negatif $\left(d_{i}{ }^{-}-d_{i}{ }^{+}\right)$sama dengan 0 . Rata-rata produksi crumb rubber tahun 2020 untuk SIR 3L yaitu 94.429, SIR 10 yaitu 194.860 dan SIR 20 yaitu 30.309.

b. Sasaran untuk memaksimalkan pendapatan dari penjualan crumb rubber SIR 3L, SIR 10 dan SIR 20 sudah terpenuhi karena sudah mencapai target perusahaan yaitu sebesar $\geq \mathrm{Rp}$ 1.000.000.000 per bulan.

c. Sasaran untuk memaksimalkan kapasitas mesin dari bulan Januari sampai dengan bulan Desember tahun 2020 untuk SIR 3L, SIR 10 , dan SIR 20 belum tercapai karena masih ada sisa waktu yang dapat dioptimalkan dan rata-rata sisa waktu tersebut adalah sebesar 46.784 menit per bulan.

d. Sasaran untuk mamaksimalkan jam kerja lembur dari bulan Januari sampai dengan bulan Desember tahun 2020 untuk SIR 3L, SIR 10 dan SIR 20 tahun 2020 sudah tercapai dan memenuhi target minimal perusahaan yaitu sebesar 1200 menit per bulan.

Sebagian dari hasil perencanaan produksi crumb rubber untuk SIR 3L, SIR 10 dan SIR 20 tahun 2020 di PT. Bakrie Sumatera Plantations Tbk. sudah memenuhi target perusahaan.

\section{Daftar Pustaka}

[1] Amrine, H. T. (1986, Januari 26). Manajemen dan Organisasi Produksi. Jakarta: Erlangga,h. 269-275.

[2] Baroto, T. (2002). Perencanaan dan Pengendalian Produksi. Jakarta: Ghalia Indonesia,h. 13-14.

[3 ] Damanik, E., Gultom, P., \& Nababan, E. S. (2013). Penerapan Metode Goal Programming Untuk Mengoptimalkan Produksi Teh (Studi Kasus: Pt Perkebunan Nusantara Iv - Pabrik Teh Bah Butong). Jurnal Saintia Matematika. Vol. 1, No. 2: pp. 117-128, h. 117-118.

[4 ] D. Sutrisno, A. Sahari, \& D. Lusiyanti (2017). "Aplikasi metode goal programming pada perencanaan produksi klappertaart pada usaha kecil menengah (UKM) najimah klappertaart"

[5] Gita Sari (2018). “Optimasi Perencanaan Produksi Kopi Bubuk Dengan Metode Goal Programming
Berbasis Qm For Windows (Studi Kasus Industri Rumahan Kopi Bubuk Sr Asli Lampung Di Waydadi, Kecamatan Sukarame)"

[6] Montgomery, D.C. (2009) Introduction to Statistical Quality Control. 6th Edition, John Wiley \& Sons, New York.

[7 ] Noviana Rahmawati (2012). "Forecasting Penjualan Sepeda Motor Kawasaki Pada Pt. Sumber Buana Motor Yogyakarta Tahun 2013"

[8 ] Pupy Ajiningtyas, Suhud Wahyudi, \& Farida Agustini W (2013). "Penerapan metode goal programming untuk perencanaan produksi pada produk olahan tebu"

[9] Roni, K., Dwi Rustam \& Awan M (2010). "Model Optimasi Tanam pada Lahan Kering di Desa Sarimulti Kecamatan Pasirwangi Kabupaten Garut"

[10 ] Siringoringo, H. (2005). Seri Teknik Riset Operasional Pemrograman Linear, Yogyakarta :Graha IImu,h. 16-18. 